\title{
BMJ Open The NHS Health Check programme: implementation in east London 2009-2011
}

\author{
John Robson, ${ }^{1}$ Isabel Dostal, ${ }^{1}$ Vichithranie Madurasinghe, ${ }^{1}$ Aziz Sheikh, ${ }^{2}$ \\ Sally Hull, ${ }^{1}$ Kambiz Boomla, ${ }^{1}$ Helen Page,${ }^{3}$ Chris Griffiths, ${ }^{1}$ Sandra Eldridge ${ }^{1}$
}

To cite: Robson J, Dostal I, Madurasinghe $\mathrm{V}$, et al. The NHS Health Check programme: implementation in east London 2009-2011. BMJ Open 2015;5:e007578. doi:10.1136/bmjopen-2015007578

- Prepublication history for this paper is available online. To view these files please visit the journal online (http://dx.doi.org/10.1136/ bmjopen-2015-007578).

Received 3 January 2015 Accepted 21 January 2015

CrossMark

For numbered affiliations see end of article.

Correspondence to Dr John Robson; j.robson@qmul.ac.uk

\section{ABSTRACT}

Objectives: To describe implementation and results from the National Health Service (NHS) Health Check programme.

Design: Three-year observational open cohort study: 2009-2011.

Participants: People of age 40-74 years eligible for an NHS Health Check.

Setting: 139/143 general practices in three east London primary care trusts (PCTs) serving an ethnically diverse and socially disadvantaged population.

Method: Implementation was supported with education, IT support and performance reports. Tower Hamlets PCT additionally used managed practice networks and prior-stratification to call people at higher cardiovascular (CVD) risk first.

Main outcomes measures: Attendance, proportion of high-risk population on statins and comorbidities identified.

Results: Coverage 2009, 2010, 2011 was 33.9\% (31 878/10 805), 60.6\% (30 757/18 652) and 73.4\% (21 194/28 890), respectively. Older people were more likely to attend than younger people. Attendance was similar across deprivation quintiles and was in accordance with population distributions of black African/Caribbean, South Asian and White ethnic groups. 1 in 10 attendees were at high-CVD risk (20\% or more 10-year risk). In the two PCTs stratifying risk, $14.3 \%$ and $9.4 \%$ of attendees were at high-CVD risk compared to $8.6 \%$ in the PCT using an unselected invitation strategy. Statin prescription to people at highCVD risk was higher in Tower Hamlets $48.9 \%$, than in City and Hackney $23.1 \%$ or Newham $20.2 \%$. In the 6 months following an NHS Health Check, 1349 new cases of hypertension, 638 new cases of diabetes and 89 new cases of chronic kidney disease (CKD) were diagnosed. This represents 1 new case of hypertension per 38 Checks, 1 new case of diabetes per 80 Checks and 1 new case of CKD per 568 Checks.

Conclusions: Implementation of the NHS Health Check programme in these localities demonstrates limited success. Coverage and treatment of those at high-CVD risk could be improved. Targeting invitations to people at high-CVD risk and managed practice networks in Tower Hamlets improved performance.

\section{Strengths and limitations of this study}

- Observational 3-year study of National Health Service (NHS) Health Check implementation in three of the most ethnically diverse and disadvantaged boroughs in the UK.

- In 2011, coverage averaged $73 \%$ with no evidence of under-representation by black African/ Caribbean, South Asian or White ethnic groups or deprivation quintile.

- One primary care trust (PCT) using prior risk estimates for inviting the highest risk first, identified $66 \%$ more people at high risk. Overall, 1 in 10 people were at high-cardiovascular disease risk and in these people statin prescription was $20 \%, 23 \%$ and $49 \%$ in the three PCTs, respectively.

- One new case of hypertension was diagnosed per 38 Health Checks, 1 case of diabetes per 80 Checks and 1 case of chronic kidney disease per 568 Checks.

- Implementation had 'home advantage' through a single IT system supported by the University Clinical Effectiveness Group. Additionally, Tower Hamlets PCT managed practice networks contributed to their programme success. There was no control group and this study provides limited evidence of effectiveness.

\section{INTRODUCTION}

In England, the National Health Service (NHS) Health Check is the first programme internationally aiming to improve cardiovascular disease (CVD) risk factors in an entire national adult population through behavioural change and treatment informed by CVD risk stratification. Those eligible are aged 40-74 years without diabetes or cardiovascular disease. The rolling 5-year programme invites one-fifth of the eligible population annually, aiming for 3 million people at a cost of $£ 165$ million. ${ }^{1-3}$ The Department of Health report that 2.3 million NHS Health Checks were undertaken in the 
2 years 2011-2012. ${ }^{4}$ Nationally, uptake is reported at around $50 \%$ with considerable variability. ${ }^{4-6}$ Since 2013 , the programme has been supported by NHS England and Public Health England, with commissioning transferred to the Local Authorities. ${ }^{78}$

There is no doubt that public health and legislative measures on the causes of CVD are the major drivers for improvement, including action on smoking, dietary saturated fats, salt, sugars, alcohol, better air quality and safer built environments promoting physical activity. ${ }^{9}$ Yet despite huge gains since the epidemic peak in the 1970s, CVD remains the greatest cause of premature death.

Treatment of people at highest CVD risk and health promotion for the general population have a substantial evidence base. ${ }^{10}$ In people at increased cardiovascular (CVD) risk, primary prevention of CVD using multiplerisk factor intervention, including treatment with statins and antihypertensives, has been shown to be of benefit. ${ }^{11}$ For people at lower CVD risk, the efficacy of health checks remains unclear. ${ }^{12}$

The NHS Health Check programme aims to prevent CVD events and detect diabetes, chronic kidney disease (CKD) and hypertension. Stratification of CVD risk to guide treatment is a key component. At the time of the study, National Institute for Health and Care Excellence (NICE) guidance recommended statin treatment for a 10 -year CVD risk of $20 \%$ or more, with appropriate management of new comorbidities. ${ }^{13} 14$

We describe implementation of the NHS Health Check programme in Newham, Tower Hamlets and City and Hackney Primary Care Trusts (PCTs). In 2013, PCTs became Clinical Commissioning Groups and responsibility for the NHS Check Programme was transferred to local authorities, and NHS England and Public Health England. These organisations serve some of the most ethnically diverse and socially deprived populations in the UK and $50 \%$ of the population of 850000 people were from ethnic minority groups, of whom $30 \%$ are South Asian and 10\% are black African/Caribbean. These three boroughs are in the top $1 \%$ of UK deprivation. Levels of premature cardiovascular death are among the highest in England, almost twice that of the English average, and higher in South Asians for whom type 2 diabetes is a major risk factor for CVD. ${ }^{15}$ High turnover of patients, extended overseas visits and changes of address and language compound the complexities of programme delivery.

This study describes the first 3 years implementation of the NHS Health Check programme, 2009-2011, in three entire PCTs, coverage and characteristics of those who attended, the distribution and management of CVD risks and the new identified comorbidities.

\section{METHODS}

\section{Data extraction and analysis}

This was a retrospective 3-year observational study on an open cohort of patients eligible for an NHS Check, based on data routinely entered by primary care staff in electronic health records 2009-2011.

All but four of the 143 general practitioner (GP) practices in the three PCTs used the same web-enabled GP electronic health record (EMIS Web). These web-enabled GP practices cover $98 \%$ of 850000 people registered with local general practices. The other four practices took part in the NHS Health Check programme, but for technical reasons were not able to provide study data.

In 2012, the Clinical Effectiveness Group QMUL extracted anonymised patient level data from these electronic health records in 139 out of a total of all 143 general practices that serve the boroughs of Newham, City and Hackney and Tower Hamlets. Data for each of the first 3 years of the NHS Health Check programme from April 2009/2010 to April 2011/2012 were extracted.

The study plan conformed to the STROBE recommendations. ${ }^{16}$ All data extracted were anonymous and based on routine data sources. Approval by an ethics committee was not necessary. The data was analysed using STATA V.10 (STATA Corps) and $\chi^{2}$ tests were used to compare proportions.

\section{Implementation of the NHS Health Checks}

NHS Health Checks were largely undertaken by general practice-based Health Care Assistants first employed in 2009 and trained to undertake NHS Health Checks. Practice nurses or GPs also did some Checks.

The NHS Health Check typically took 20-30 min. 10-year risk of CVD was estimated using QRisk2 (http:// www.qrisk.org), and fully integrated with the GP electronic health record in all study practices. Blood was taken for serum total cholesterol and high-density lipoprotein cholesterol with additional tests in those at high-CVD risk for glycaemia, renal and liver function and glycaemia in those with a body mass index of 30 or more. Alcohol consumption with appropriate advice was included but not nationally recommended at the time.

Attendees were advised on modification of ameliorable risk factors. Appointments with GP clinical staff were made for further management of risk factors and referrals were made to local providers supporting behavioural change for smoking, diet, physical activity and alcohol use. ${ }^{13}$

People at high-CVD risk (those with a 10-year CVD risk of $20 \%$ or more) were considered for statin treatment. Patients with risk factors such as abnormal glycaemia, raised blood pressure, abnormal estimated-glomerular filtration rate (eGFR) or liver function tests were investigated for potential comorbid diagnoses, including hypertension, diabetes, chronic kidney or liver disease. Continuing annual follow-up of those at high-CVD risk was advised either as part of an established treatment pathway (hypertension, chronic kidney disease, diabetes) or as an ongoing annual review of high-CVD risk status; however, only in Tower Hamlets and City and Hackney 
did this follow-up receive a financial incentive in the study period.

The Clinical Effectiveness Group (CEG) is a quality improvement group led by academic GPs based in the local University, funded at the time by the three PCTs and currently by the Clinical Commissioning Groups that succeeded them in 2013, to support a range of improvement initiatives. CEG supported implementation of the NHS Health Check programme, producing local guidelines summarising national policies and educational meetings. CEG also developed IT support with a standard on-screen data entry template to ensure that a standard codeset was used in every practice. This established a robust system for accurate data capture, regular feedback of performance dashboards and payment reports, and creation of standardised searches for practice call/recall systems. In Tower Hamlets, performance dashboards were also reported at the network level. The local NHS Health Check 2009 guideline and data entry templates are available on the CEG website. http:// blizard.qmul.ac.uk/ceg-resource-library.html

CEG also organised prior estimates of CVD risk by using QRisk2 in all eligible patients in each practice in Tower Hamlets and City and Hackney, as described below.

\section{Differences between PCTs}

In all three PCTs, the implementation of the programme was supported by local schemes which paid GPs to undertake the NHS Health Checks. City and Hackney paid £12, £27 or $£ 44$ depending on whether the identified 10-year CVD risk was $0-9 \%, 10-19 \%$ or $20 \%$ or more. Payment for NHS Health Checks in Newham in the initial 6-month was $£ 50$ to encourage start-up of the programme and then reduced to $£ 35$. Both Hackney and Tower Hamlets (but not Newham) financially incentivised targets for coverage, for the proportion of highrisk individuals on statins and for follow-up of those at high-CVD risk who were not already on existing hypertension or other management programmes. In Tower Hamlets, GPs were initially paid £11 per completed Check, but practices were also funded to employ 1-2 trained Healthcare Assistants depending on practice size. From 2010, the programme in Tower Hamlets was additionally supported by the formation of managed practice networks, described below, with financial incentives paid on the basis of network achievement of targets rather than individual practice performance. If targets were met, Tower Hamlets paid $£ 32$ per completed Check.

There were other differences between implementation in the three PCTs. In Tower Hamlets and City and Hackney in 2009, CEG estimated prior CVD risk in every eligible patient based on data in their medical record so that those at highest risk could be called first. Practices subsequently varied in the extent to which they used this facility to update the risk estimates; this was most complete in Tower Hamlets. Newham started their programme as a pilot 6 months before the April 2009 national start date. Prior stratification of risk was not possible in Newham until 2011/2012. Therefore, in Tower Hamlets and City and Hackney, patients at highest risk were selected first for invitation whereas little or no stratification took place in Newham. Network managers ensured that stratified invites were most complete in Tower Hamlets, while in Hackney it was more variably implemented.

In Newham, but not the other PCTs, cholesterol and random blood glucose measurement were undertaken as point of care testing in all attendees. In the other two PCTs, samples were sent to hospital laboratories and fasting blood glucose was selectively taken in people who were obese or at high-CVD risk.

In Newham, five pharmacies carried out some NHS Health Checks and in each of the PCTs a small number of Checks were provided in community settings. These comprised fewer than $2 \%$ of total NHS Health Checks. The results of these Checks were intended to be recorded in the GP records, but the results cannot be separately identified to assess the completeness of recording.

\section{Tower Hamlets managed practice networks}

Tower Hamlets PCT established managed practice networks in 2009, grouping general practices into geographical networks of 4-5 practices serving populations of $30000-50000$; each had a network manager to deliver four care packages-diabetes, childhood immunisation, chronic lung disease and CVD. NHS Health Checks were one element of the CVD care package fully implemented in 2010, with payment for 3 key performance indicators: NHS Check coverage, statin usage in people at high-CVD risk and follow-up of those at high-CVD risk. These managed practice networks produced a step-change in performance for Tower Hamlets which was the top CCG in England in 2012/2013 across a range of measures for diabetes, COPD and CVD in the national Quality and Outcomes Framework and national diabetes audit, and top in London for childhood immunisation. ${ }^{17-19}$

\section{Definitions of variables used}

The current Department of Health (DOH) definition of the eligible population includes people aged $40-74$ years and excludes those with pre-existing coronary heart disease, stroke/transient ischaemic attack, peripheral vascular disease, heart failure, atrial fibrillation, hypertension, diabetes, familial hypercholesterolaemia, CKD stages 3-5 and people already on statins.

Ethnic group data was based on self-reported ethnicity recorded in the GP electronic health record. For the purposes of this study, data were grouped by 2001 Census category: white (British, Irish, other white); South Asian (Bangladeshi, Indian, Pakistani, other Asian); black (African, Caribbean, black British); other (any other recorded ethnic group including mixed 
Table 1 Total eligible population (EP), number and proportion of attendees and coverage*

\begin{tabular}{|c|c|c|c|c|}
\hline Year & Total EP & Attendees & EP attended (\%) & Coverage (\%) \\
\hline \multicolumn{5}{|l|}{ Newham } \\
\hline 2009-2010 & 51353 & 8477 & 16.5 & 82.5 \\
\hline 2010-2011 & 46980 & 6310 & 13.4 & 67.2 \\
\hline $2011-2012$ & 45450 & 7346 & 16.2 & 80.8 \\
\hline Total & & 22133 & & \\
\hline \multicolumn{5}{|c|}{ City and Hackney } \\
\hline 2009-2010 & 63258 & 730 & 1.2 & 5.8 \\
\hline 2010-2011 & 62930 & 6759 & 10.7 & 53.7 \\
\hline 2011-2012 & 58390 & 6939 & 11.9 & 59.4 \\
\hline Total & & 14428 & & \\
\hline \multicolumn{5}{|l|}{ Tower Hamlets } \\
\hline 2009-2010 & 44779 & 1598 & 3.6 & 17.8 \\
\hline 2010-2011 & 43875 & 5583 & 12.7 & 63.6 \\
\hline 2011-2012 & 40611 & 6909 & 17.0 & 85.1 \\
\hline Total & & 14090 & & \\
\hline \multicolumn{5}{|l|}{ All 3 PCTs } \\
\hline 2009-2010 & 159390 & 10805 & 6.8 & 33.9 \\
\hline 2010-2011 & 153785 & 18652 & 12.1 & 60.6 \\
\hline 2011-2012 & 144451 & 21194 & 14.7 & 73.4 \\
\hline Total & & 50651 & & \\
\hline
\end{tabular}

ethnic groups) and not stated (ethnicity could not be classified from the recorded entry). Those without a record were categorised as not recorded. Over $90 \%$ of the adult population in these PCTs had a GP record of their self-reported ethnic group.

New comorbidity was defined as a new diagnosis of hypertension or diabetes recorded within 6 months of the Health Check, and not simply a raised blood pressure or hyperglycaemia. CKD was defined by an eGFR of less than $60 \mathrm{~mL} / \mathrm{min} / 1.73 \mathrm{~m}^{2}$. Statin prescription was any prescription recorded following an NHS Check.

Deprivation was assessed using the Townsend score accessed for $99 \%$ of patients, based on 2001 Census-derived measures of overcrowding, car ownership and education available at lower super output area; approximately 150 households.

Invitations for NHS Health Checks were not recorded as no codes for invitation existed in the initial years. In this study, coverage is defined as the proportion of onefifth of the total eligible population in that year who attended for an NHS Health Check. In other words, if $14 \%$ of the total eligible population attended in 1 year, that represents a coverage of $14 / 20=70 \%$. This differs from current NHS England reports of uptake, defined as attendees as a proportion of those invited to attend.

The programme was implemented at varying start dates in the three PCTs. In Newham, it was started in 2008, 6 months before the official start on 1 April 2009. In Tower Hamlets, and City and Hackney, the implementation was not complete in all practices until 2010.

\section{RESULTS}

Table 1 shows that in the years April 2009-2011 across all three PCTs, 50651 people attended an NHS Health Check. This represents $6.8 \%, 12.1 \%$ and $14.7 \%$ of the total eligible population in each successive year, equivalent to coverage of $33.9 \% \quad(31878 / 10805), 60.6 \%$ (30 757/18 652) and 73.4\% (21 194/28 890) in each year, respectively. By 2011/2012, Newham and Tower

Table 2 Total eligible and total attendees; numbers and proportions of these aged 60-74; 2011/2012

\begin{tabular}{|c|c|c|c|c|c|c|}
\hline & \multirow{2}{*}{$\begin{array}{l}\text { Total eligible } 40-74 \text { years } \\
\mathrm{N}\end{array}$} & \multicolumn{2}{|c|}{ Eligible $60-74$ years } & \multirow{2}{*}{$\begin{array}{l}\text { Total attendees } \\
40-74 \text { years }\end{array}$} & \multicolumn{2}{|c|}{$\begin{array}{l}\text { Attendees } \\
60-74 \text { years }\end{array}$} \\
\hline & & $\mathbf{N}$ & Total (\%) & & $\mathbf{N}$ & Total (\%) \\
\hline Tower Hamlets & 40611 & 4011 & 9.9 & 6909 & 1011 & 14.6 \\
\hline City and Hackney & 58390 & 6723 & 11.5 & 6939 & 1258 & 18.1 \\
\hline Newham & 45450 & 4796 & 10.6 & 7346 & 869 & 11.8 \\
\hline All 3 PCTs & 144451 & 15530 & 10.8 & 21194 & 3138 & 14.8 \\
\hline
\end{tabular}


Hamlets had coverage of $82.5 \%$ and $85.1 \%$, respectively, and City and Hackney of $59.4 \%$.

\section{Characteristics of attendees}

Table 2 shows that attendees at an NHS Health Check were significantly older than would be expected from their distribution in the eligible population. Over all three PCTs in 2011/2012, people aged 60 years or more comprised $14.8 \%$ of NHS Health Check attendees compared to $10.8 \%$ in the eligible population $(\mathrm{p}<0.001)$.

Owing to the strategy of calling people at high-CVD risk first, older people were more likely to attend in Tower Hamlets, and City and Hackney than in Newham. In Newham, 2011/2012, people aged 60 years or more comprised $11.8 \%$ of attendees compared to $10.6 \%$ of those in the eligible population. In City and Hackney, of the 2011/2012 attendees, aged 60 years and over comprised $18.1 \%$ compared to $11.5 \%$ of those in the eligible population and in Tower Hamlets, this age group comprised $14.6 \%$ of attendees compared to $9.9 \%$ in the eligible population.

Table 3 shows that attendance among black African/ Caribbean, South Asian and White ethnic groups was similar to their representation in the eligible population and no group was under-represented. Attendance by 'Other' ethnic groups and in particular, by those without ethnic group recorded were lower than expected. In 2011-2012, over all three PCTs, the proportion of black African/Caribbean people in the eligible population and their proportion among attendees comprised $19.8 \%$ and $21.6 \%$, respectively; proportion for South Asian was $15.4 \%$ and $23.6 \%$; White $42.2 \%$ and $46.9 \%$; Other $8.5 \%$ and $6.8 \%$; Not Recorded $14.2 \%$ and $0.1 \%$, respectively.

Across all three PCTs, the coverage was similar across all deprivation groups and those in the most deprived quintile comprised $82 \%$ of attendees and $80 \%$ of the eligible population.

\section{CVD risk}

Over the period 2009-2011, QRisk2 was recorded in $94.1 \%(47648 / 50651)$ attendees at an NHS Health Check and 56.8\% (231 158/406 975) of non-attendees. Among those with a QRisk2 recording, high-CVD risk was recorded in $10.5 \%(4990 / 47648)$ of attendees and $5.1 \%(11794 / 231158)$ of non-attendees.

The number and proportion of attendees by CVD risk categories are recorded in table 4 for the three combined PCTs over all the 3 years; $33.3 \%$ of attendees were at $10 \%$ or more CVD risk, and $10.5 \%$ were at $20 \%$ or more CVD risk.

Table 5 shows the proportions of attendees who were at high-CVD risk (QRisk2 20\% or more 10-year risk) in each of the 3 years. As people at highest CVD risk tended to be selected first in Tower Hamlets, and City and Hackney, there were relatively more attendees at high CVD risk in earlier years. By the third year of the programme, there was less difference between PCTs in

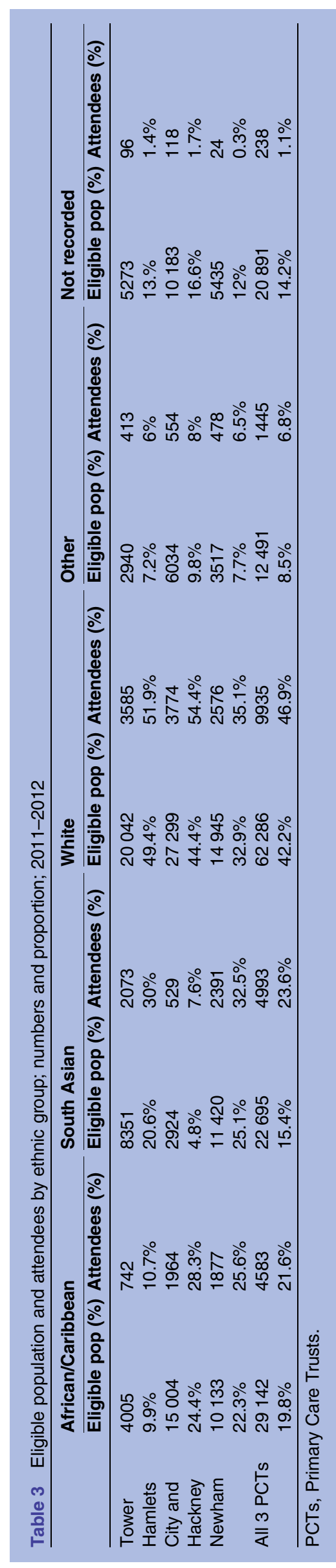


Table 4 People attending an NHS Health Check by CVD 10-year risk (QRisk2)

\begin{tabular}{lllllll}
\hline CVD risk & $\mathbf{0 - < 5 \%}$ & $\mathbf{5 - < 1 0 \%}$ & $\mathbf{1 0 - < 1 5 \%}$ & $\mathbf{1 5 - < 2 0 \%}$ & $\mathbf{2 0 \% +}$ & All \\
\hline Per cent in risk group & $40.3 \%$ & $26.4 \%$ & $14.3 \%$ & $\mathbf{8 . 5 \%}$ & $10.5 \%$ & $100 \%$ \\
Number & 19203 & 12569 & 6811 & 4075 & 4990 & 47648 \\
\hline
\end{tabular}

Three PCTs 2009-2011; \%, Number

CVD, cardiovascular disease; NHS, National Health Service.

the proportion identified at high-CVD risk. However, over all 3 years, City and Hackney, which operated a selective strategy, identified more people at high-CVD risk $9.4 \%$ than Newham $8.6 \%, \mathrm{p}<0.01$; Tower Hamlets $14.3 \%$, identified significantly more than either of the other PCTs, $\mathrm{p}<0.001$. In relative terms, this targeted strategy identified $66 \%$ more people at high-CVD risk in Tower Hamlets than an unselected strategy in Newham.

QRisk2 in Tower Hamlets and City and Hackney was estimated for the entire eligible population in the first year of the programme and practices were encouraged to maintain this. In these PCTs, the proportion of nonattendees with QRisk2 recorded in 2009/2010 was $87.1 \%$ and $87.9 \%$, respectively, and by $2011 / 2012$ this had fallen to $76.1 \%$ and $40.7 \%$, respectively. In Newham in 2009/2010, 21.7\% of non-attendees had QRisk2 recorded and this increased to $45.2 \%$ in $2011 / 2012$ as some practices in Newham adopted prior stratification in the latter year.

\section{Treatment in people at high risk}

There were marked differences between the three PCTs in the proportion of people at high-CVD risk prescribed statins shown in table 6 . Prescription of statins to people at high-CVD risk in 2009-2011 was consistently higher in Tower Hamlets $48.9 \%$ than in the other two PCTs; City and Hackney 23.1\%, and Newham 20.2\%. Across all three PCTs combined in the years beginning 2009-2011, the proportion at high-CVD risk prescribed statins was similar at $34.6 \%, 30.9 \%$ and $31.9 \%$. Less than $1 \%$ had a statin contraindication recorded.

\section{New comorbidities}

In the three PCTs in the years 2009-2011, there were a total of 50651 NHS Health Checks and in the 6 months following, 1349 new cases of hypertension were diagnosed as were 638 new cases of diabetes and 89 new cases of CKD. This represents one new case of hypertension per 38 Checks, one new case of diabetes per 80 Checks, and one new case of CKD per 568 Checks.

Table 7 shows the new comorbidities identified within 6 months per 1000 NHS Health Checks. Tower Hamlets had higher rates of newly identified hypertension and CKD than the other two PCTs $(p<0.001)$. The incidence of new diabetes diagnoses was similar in Tower Hamlets and Newham despite the fact that Newham has a higher background prevalence of diabetes and blood glucose testing was undertaken at all NHS Health Checks in Newham; Tower Hamlets restricted tests to a higher risk group.

\section{DISCUSSION}

This is the most extensive report of the NHS Health Check programme to date, describing implementation and first 3 years results in three entire local health economies.

Differences in implementation between PCTs permit some comparative assessment of identified comorbidities and statin prescription. All three PCTs actively supported the programme with financial incentives, staff training, educational programmes, IT support and feedback of performance. Tower Hamlets achieved the best results with additional support through managed practice networks in combination with prior risk stratification.

In the 3 years $2009-2011,6.8 \%, 12.1 \%$ and $14.7 \%$ of the eligible population aged 40-74 years attended an NHS Health Check, representing coverage of 33.9\%, $60.5 \%$ and $73.5 \%$, respectively. This is comparable to coverage by the well-established national breast screening programme, with London uptake of $64 \%$ in 2010/ 2011 and cervical screening in east London of $72 \%$ in 2010/2011; these exceeded the $40 \%$ uptake of the more recently established bowel screening programme. ${ }^{20} 21$ Other studies report improved uptake from the synergy of GP practice based support for recall systems. ${ }^{22}$

Table 5 Attendees in the high-CVD risk group by year and PCT.

\begin{tabular}{lcccr}
\hline & $\mathbf{2 0 0 9}$ & $\mathbf{2 0 1 0}$ & $\mathbf{2 0 1 1}$ & All years \\
\hline Newham & $9.2 \% 733$ & $8.2 \% 458$ & $8.1 \% 524$ & $8.6 \% 1715$ \\
City and Hackney & $23.6 \% 150$ & $9.9 \% 640$ & $7.8 \% 538$ & $9.4 \% 1328$ \\
Tower Hamlets & $31.3 \% 484$ & $16.5 \% 882$ & $8.6 \% 581$ & $14.3 \% 1947$ \\
All PCTs & $13.4 \% 1367$ & $11.4 \% 1980$ & $8.2 \% 1643$ & $10.5 \% 4990$ \\
\hline
\end{tabular}

\%; Number 2009-2011.

CVD, cardiovascular disease; NHS, National Health Service; PCTs, primary care trusts. 
Table 6 Percentage of attendees at high-CVD risk prescribed a statin, by PCT and year

\begin{tabular}{|c|c|c|c|c|}
\hline & $\begin{array}{l}\text { 2009-2010 } \\
\text { Attendees (\%) }\end{array}$ & $\begin{array}{l}2010-2011 \\
\text { Attendees (\%) }\end{array}$ & $\begin{array}{l}\text { 2011-2012 } \\
\text { Attendees (\%) }\end{array}$ & $\begin{array}{l}2009-2011 \\
\text { All Attendees (\%) }\end{array}$ \\
\hline Newham & 25.2 & 16.4 & 16.4 & 20.2 \\
\hline City and Hackney & 27.3 & 22.2 & 23.8 & 23.2 \\
\hline Tower Hamlets & 51.0 & 44.8 & 53.4 & 48.9 \\
\hline All 3 PCTs & 34.6 & 30.9 & 31.9 & 32.2 \\
\hline
\end{tabular}

PCTs, Primary Care Trusts.

By 2011, 20000 people attended annually for an NHS Health Check in these three PCTs and in total 50651 people attended since 2009. The level of coverage in 2011 was $85 \%$ in Tower Hamlets though coverage was similarly high in Newham, where the PCT had been particularly proactive with financial and facilitative support. There was no evidence of underprovision for older people, those in the major ethnic minority groups or for the most deprived quintiles. Under-representation of other ethnic groups and those without ethnicity recorded is likely to be due to people who had left the practice or no longer lived at their stated address.

Over the study period, 1 in 10 attendees were at high-CVD risk (20\% or more 10-year risk). In Tower Hamlets and City and Hackney PCTs which per-stratified invitations, $14.3 \%$ and $9.4 \%$ of attendees were at high risk compared to $8.6 \%$ using an unselected strategy in Newham $(p<0.01)$. In Tower Hamlets, this represents a $66 \%$ increase in attendance from among those at high-CVD risk in comparison to an unselected strategy in Newham.

The prior risk estimates depend on regular annual practice updates as new patients join or age, and risks change. Over a full 5-year cycle, prior estimation of risk may represent a more efficient method of identifying those at highest risk, but would require support to encourage practices to run regular updates; alternatively age is a simple initial proxy for risk.

\section{Comparison with other studies}

In 2011, coverage in east London of $73 \%$ was higher than other reported studies. National PCT reports indicate that uptake (based on attendance among those invited) in England was 51\% in 2011. Twenty-seven of 151 PCTs nationally offered NHS Health Checks to fewer than $10 \%$ of eligible individuals. ${ }^{23}$ This reflects reports of uncertainty about the organisation, fidelity and implementation of NHS Health Checks, available codesets and of the accuracy of PCT reports of the eligible denominator population in the early years of the programme. ${ }^{524}$ There has since been standardisation of reporting. ${ }^{25}$

Earlier studies on NHS Health Checks in people at high-CVD risk reported similarly higher proportions of older people attending and similarly no underrepresentation among the South Asian or black African/ Caribbean groups, with an uptake of $20-45 \%$ and marked practice variation. ${ }^{26}{ }^{27}$ Data from Stoke on Trent found higher response among more affluent people. ${ }^{28}$ A study in one PCT, 2008/2009, in high-risk people described a reduction in CVD risk factors 1 year after an NHS Health Check and statin prescription increased from $16 \%$ to $60 \% .^{29}$

The $10.5 \%$ at high-CVD risk in our study is similar to the proportion reported in these studies from similar populations, but higher than the national average of $8.4 \%$ reflecting the higher levels of social deprivation and South Asian ethnicity in studies from inner London. ${ }^{30} 31$

In our study $32 \%$ of people at high-CVD risk were prescribed statins. In an English nationally representative study, Van $\mathrm{Staa}^{32}$ also found that $32 \%$ of those at high-CVD risk in 2010 were prescribed statins. Like Van Staa, we found marked differences in statin prescribing between PCTs. Twice as many people in Tower Hamlets were prescribed statins $49 \%$, than in City and Hackney $23 \%$ or Newham $20 \%$. Other UK studies have shown rates of statin treatment of $45 \%$ and $53 \%$ in selected people at high-GVD risk ${ }^{26}{ }^{27}$ and in New Zealand, statin use is between 20 and $32 \% .^{33}$

Table 7 New diagnoses of hypertension, diabetes and CKD within $6 \mathrm{~m}$ of NHS Health Check by PCT 2009-2011

\begin{tabular}{llllllll}
\hline PCT & $\begin{array}{l}\text { Hypertension } \\
\text { Rate }\end{array}$ & N & $\begin{array}{l}\text { Diabetes } \\
\text { Rate }\end{array}$ & N & $\begin{array}{l}\text { CKD 3-5 } \\
\text { Rate }\end{array}$ & N & $\begin{array}{l}\text { Total } \\
\text { attendees }\end{array}$ \\
\hline Newham & 22.7 & 503 & 14.4 & 318 & 1.7 & 37 & 22133 \\
City and Hackney & 23.5 & 339 & 9.2 & 133 & 0.8 & 11 & 14428 \\
Tower Hamlets & 36.0 & 507 & 13.3 & 187 & 2.9 & 41 & 14090 \\
All 3 PCTs & 26.6 & 1349 & 12.6 & 638 & 1.8 & 89 & 50651 \\
\hline
\end{tabular}

Rate per 1000 Health Checks, number.

CKD, chronic kidney disease; NHS, National Health Service; PCTs, Primary Care Trusts. 
The identification of new comorbidities has been a successful element of this current programme. One new case of diabetes was identified for every 80 Checks carried out and 1 new case of hypertension for every 38 Checks carried out. New comorbidities will be detected in primary care in the absence of NHS Health Checks and the 'additional' cases identified have not been estimated in this evaluation as this would be more appropriate to consider in a full 5-year cycle of the programme. Existing strategies to detect diabetes may still be suboptimal and specific risk scores to target diabetes or renal risk may improve detection rates. ${ }^{34-36}$

\section{Differences between study PCTs}

The relatively high rate of statin prescription in Tower Hamlets was influenced by two factors. First, Tower Hamlets targeted people in the highest risk categories. Those people with CVD risks as high as $40 \%$ or $50 \%$, for example, will be older or have a positive family history of premature heart attack, obesity or South Asian ethnic group, each of which may positively influence perception of risk and take-up of statin treatment. ${ }^{37} 38$ Second, managed practice networks produced a step-change in local performance in Tower Hamlets.

All three PCTs had similar levels of core support from the Clinical Effectiveness Group. Tower Hamlets and City and Hackney additionally targeted high-risk people. In Newham, an early 2008 start and higher financial incentives promoted rapid adoption of the programme. In Tower Hamlets, the NHS Health Check programme was incorporated into the Tower Hamlets managed practice network scheme with targets for coverage, statins and follow-up of people at high-CVD risk.

Although Newham achieved similar coverage to Tower Hamlets, their programme did not target people at high-CVD risk and this led to the identification of a lower risk group; $8.6 \%$ at high-CVD risk compared to $14.3 \%$ in Tower Hamlets. This is likely to be one of the main reasons why relatively less hypertension and CKD was identified in Newham and City and Hackney. Managed practice networks are also likely to have contributed to higher statin prescription in Tower Hamlets. Diabetes identification in Newham and Tower Hamlets was similar because the prevalence of type 2 diabetes is known to be highest in Newham where universal blood glucose testing was used. (a more targeted strategy was subsequently adopted in Newham as this proved an inefficient method of screening).

\section{Strengths and weaknesses}

Our between group comparisons used a simple $\chi^{2}$ test. The use of multiple logistic regression would have given greater precision, but would not have altered the above conclusions. The first 3-years of a programme assessment may not reflect performance in a full 5 -year cycle.

The study is based on almost all practices in three localities rather than selected practices, giving a complete picture of implementation. All three PCTs were enthusiastic early adopters of the programme with 'home advantage' support from the University-based Clinical Effectiveness Group. The alignment of strategies-education through guidelines and meetings, a single IT system and performance feedback were key to synergistic working. CEG produced guidelines, supported education and Health Care Assistant training, designed standard coding and data entry templates, decision support tools, prior-stratification invite lists together with training and continuing support, including monthly identifiable practice performance reports on key indicators.

An unintended consequence of the NHS Check programme was the employment and training of Health Care Assistants. Many were GP reception and clerical staff, keen to develop skills and capacity. They now form an important part of the local workforce with broader responsibilities and training formalised in National Vocational Qualification schemes.

\section{Wider context of NHS Checks}

Nationally, NHS Check implementation has been highly variable and lower than expected. Higher uptake in deprived areas reduces the possibility of exacerbation of inequalities. ${ }^{6}{ }^{39}$ In some CCGs nationally, uncertainty about the benefits of such programmes and claims that health checks are ineffective may have contributed to a lack of investment in new services at a time of reduced NHS budgets. These views, which received a large amount of media publicity critical of the NHS Check programme, were based on studies now 20-30 years old, conducted in very different settings before most effective treatments for blood pressure, lipids and therapies for smoking cessation were invented. ${ }^{40-43}$ More recently, major organisational change in the NHS in 2013, when PCTs became Clinical Commissioning Groups and responsibility for the programme was transferred to local authorities at a time of reduced budgets, have also been reported to have impacted on implementation. ${ }^{44} \mathrm{~A}$ range of issues are currently being addressed by NHS England and Public Health England. ${ }^{24}$ The transfer of commissioning responsibility has not altered the CVD content of the NHS Check and the findings of this study are relevant to current implementation of this programme.

\section{CONCLUSION}

The NHS Health Check programme was successfully implemented across all primary care organisations in three of the most disadvantaged boroughs in the UK, achieving $73 \%$ annual coverage by 2011 and delivering 20000 NHS Health Checks annually. Older people were more likely to attend and attendance among black African/Caribbean, South Asian and White ethnic groups and all quintiles of deprivation reflected their representation in the local population.

One in 10 of those attending an NHS Health Check were at high-CVD risk, of whom $32 \%$ were prescribed statins, with prescription higher in Tower Hamlets at $48.9 \%$, than 
in the other two PCTs: City and Hackney $23.1 \%$ and Newham 20.2\%. One new case of hypertension per 38 Health Checks, 1 new case of diabetes per 80 Checks, and 1 new case of CKD per 568 Checks were identified.

PCTs inviting those at highest risk first, identified more people at high-CVD risk. Managed practice networks in Tower Hamlets were associated with the highest levels of coverage, new comorbidity, high-CVD risk identification and statin treatment.

\section{Author affiliations}

${ }^{1}$ Centre for Primary Care and Public Health, Queen Mary University of London, London, UK

${ }^{2}$ Centre for Population Health Sciences, the University of Edinburgh, Edinburgh, UK

${ }^{3}$ London Borough of Newham, Newham Dockside, London, UK

Acknowledgements The study depended on the work and cooperation of PCT staff, GPs and practice staff in Newham, City and Hackney and Tower Hamlets and in the latter, the network managers. Primary Care Trusts became Clinical Commissioning Groups in 2013.

Contributors JR was the principal investigator and guarantor of the study to which CG, SE and VM (Centre for Primary Care and Public Health, Queen Mary University of London) and AS (University of Edinburgh) and SH and KB were steering group members. Isabel Dostal carried out all data extraction and collation. HP directed the Newham implementation for the PCT. All authors contributed to the preparation of the manuscript.

Funding This report is independent research commissioned and funded by the Department of Health, Policy Research Programme 'Evaluation of the NHS Health Check programme 009/0052'. The research was conducted independently of the funders.

Competing interests JR is the PI and grant holder, and has received personal fees from this grant as have SE and ID. JR is an author of QRisk2 used in the assessment of CVD risk in the local populations studied. He also chaired the NICE Lipid Modification guideline CG67 2008 which first recommended the use of CVD risk assessment in routine care. JR, SH and KB all supported the implementation of the NHS Health Check programme in the three east London PCTs/CCGs in this study as clinical leads for the Clinical Effectiveness Group and were also clinical leads who received personal fees from Tower Hamlets PCT/CCG. HP was an employee of Newham PCT/CCG and directed implementation of the NHS Check programme in Newham. ViM, AS and CG have no competing interests to declare. AS is supported by The Commonwealth Fund. The views presented here are those of the author and not necessarily those of The Commonwealth Fund, its directors, officers or staff.

Ethics approval All data were anonymised and managed according to the UK NHS information governance requirements. Ethical approval was not required for the use of routinely collected anonymised data in this observational study.

Provenance and peer review Not commissioned; peer reviewed for ethical and funding approval prior to submission.

Data sharing statement No additional data are available.

Disclaimer The views expressed in this publication are those of the authors and not necessarily those of the Department of Health.

Open Access This is an Open Access article distributed in accordance with the Creative Commons Attribution Non Commercial (CC BY-NC 4.0) license, which permits others to distribute, remix, adapt, build upon this work noncommercially, and license their derivative works on different terms, provided the original work is properly cited and the use is non-commercial. See: http:// creativecommons.org/licenses/by-nc/4.0/

\section{REFERENCES}

1. Public Health England. NHS Health Check programme standards. 2014. http://www.healthcheck.nhs.uk/commissioners_and_ healthcare_professionals/national_guidance/ (accessed 5 May 2014).

2. Kerr M. NHS Health Check costs, benefits and savings. 9th NHS Health Check National Learning Network Workshop. 2012. http://www. nhshealthcheck.nhs.uk/default.aspx?alD=18 (accessed 6 May 2014).

3. Public Health England. NHS Health Check programme best practice guidance. 2013. http://www.healthcheck.nhs.uk/commissioners_and healthcare_professionals/national_guidance/ (accessed 6 May 2014).

4. Department of Health. NHS Health Checks 2011-13. http://www. england.nhs.uk/statistics/integrated-performance-measuresmonitoring/nhs-health-checks-data/ (accessed 6 May 2014).

5. Nicholas JM, Burgess $\mathrm{C}$, Dodhia $\mathrm{H}$, et al. Variations in the organization and delivery of the 'NHS health check' in primary care. J Public Health (Oxf) 2013;35:85-91.

6. Artac M, Dalton AR, Babu $\mathrm{H}$, et al. Primary care and population factors associated with NHS Health Check coverage: a national cross-sectional study. J Public Health (Oxf) 2013;35:431-9.

7. Department of Health. Living well for longer: a call to action on avoiding premature mortality. London: Department of Health, 2013.

8. Department of Health. Improving outcomes for people with or at risk of cardiovascular disease. 2013. http://www.gov.uk/government/ publications/cardiovascular-disease-outcomes-strategy-improvingoutcomes-for-people-with-or-at-risk-of-cardiovascular-disease (accessed 5 May 2014)

9. NICE. Prevention of cardiovascular disease at population level. London: National Institute for Health and Clinical Excellence, 2010.

10. Taylor F, Huffman MD, Macedo AF, et al. Statins for the primary prevention of cardiovascular disease. Cochrane Database Syst Rev 2013;1:CD004816.

11. Ebrahim S, Taylor F, Ward K, et al. Multiple risk factor interventions for primary prevention of coronary heart disease. Cochrane Database Syst Rev 2011;1:CD001561.

12. Capewell S, Lloyd-Jones DM. Optimal cardiovascular prevention strategies for the 21st century. JAMA 2010;304:2057-8.

13. Department of Health. Putting prevention first: NHS Health check: Vascular risk asessment and management. Best practice guidance. 2009. http://www.healthcheck.nhs.uk/document.php?o=227 (accessed 5 May 2014).

14. NICE. Lipid modification: cardiovascular risk assessment and the modification of blood lipids for the primary and secondary prevention of cardiovascular disease. London: National Institute of Health and Clinical Excellence, 2008.

15. South East Public Health Observatory. Cardiovascular disease local authority health profile Tower Hamlets. 2014. http://www.sepho.org.uk/ NationalCVD/docs/00BG_CVD\%20Profile.pdf (accessed 6 May 2014).

16. von Elm E, Altman DG, Egger M, et al. The Strengthening the Reporting of Observational Studies in Epidemiology (STROBE) statement: guidelines for reporting observational studies. J Clin Epidemiol 2008;61:344-9.

17. Hull S, Chowdhury TA, Mathur R, et al. Improving outcomes for patients with type 2 diabetes using general practice networks: a quality improvement project in east London. BMJ Qual Saf 2014;23:171-6.

18. Cockman $\mathrm{P}$, Dawson $\mathrm{L}$, Mathur R, et al. Improving MMR vaccination rates: herd immunity is a realistic goal. BMJ 2011;343:d5703.

19. Robson J, Hull S, Mathur R, et al. Improving cardiovascular disease using managed networks in general practice: an observational study in inner London. Br J Gen Pract 2014;64:e268-74.

20. The NHS Information Centre. Cervical screening programme England 2010-11. 2011. http://www.cancerscreening.nhs.uk/cervical/ cervical-statistics-bulletin-2010-11.pdf (accessed 6 May 2014).

21. von Wagner $\mathrm{C}$, Baio $\mathrm{G}$, Raine $\mathrm{R}$, et al. Inequalities in participation in an organized national colorectal cancer screening programme: results from the first 2.6 million invitations in England. Int J Epidemiol 2011;40:712-18.

22. Labeit A, Peinemann F, Baker R. Utilisation of preventative health check-ups in the UK: findings from individual-level repeated cross-sectional data from 1992 to 2008. BMJ Open 2013;3:e003387.

23. NHS England. NHS Health Checks Data, 2011. http://www.england. nhs.uk/statistics/statistical-work-areas/integrated-performancemeasures-monitoring/nhs-health-checks-data/ (accessed 1 Jan 2015).

24. Research Works Limited. Understanding the implementation of NHS Health Checks. Research Report. 2013; 2013(20 Feb 2014). http:// www.healthcheck.nhs.uk/document.php?o=351 (accessed 6 May 2014).

25. Health and Social Care Infromation Centre. NHS Health Check secondary use dataset. 2014. http://www.hscic.gov.uk/ nhshealthcheck (accessed 6 May 2014).

26. Dalton AR, Bottle A, Okoro C, et al. Uptake of the NHS Health Checks programme in a deprived, culturally diverse setting: cross-sectional study. J Public Health (Oxf) 2011;33:422-9. 
27. Artac M, Dalton AR, Majeed A, et al. Uptake of the NHS Health Check programme in an urban setting. Fam Pract 2013;30:426-35.

28. Cochrane T, Gidlow CJ, Kumar J, et al. Cross-sectional review of the response and treatment uptake from the NHS Health Checks programme in Stoke on Trent. J Public Health (Oxf) 2013;35:92-8.

29. Artac M, Dalton AR, Majeed A, et al. Effectiveness of a national cardiovascular disease risk assessment program (NHS Health Check): results after one year. Prev Med 2013;57:129-34.

30. Hippisley-Cox J, Coupland C, Vinogradova Y, et al. Performance of the QRISK cardiovascular risk prediction algorithm in an independent UK sample of patients from general practice: a validation study. Heart 2008:94:34-9.

31. Dalton AR, Soljak M, Samarasundera E, et al. Prevalence of cardiovascular disease risk amongst the population eligible for the NHS Health Check Programme. Eur J Prev Cardiol 2013;20:142-50.

32. van Staa TP, Smeeth L, Ng ES, et al. The efficiency of cardiovascular risk assessment: do the right patients get statin treatment? Heart 2013;99:7.

33. Mehta S, Wells S, Grey C, et al. Initiation and maintenance of cardiovascular medications following cardiovascular risk assessment in a large primary care cohort: PREDICT CVD-16. Eur J Prev Cardiol 2014;21:192-202.

34. Smith S, Waterall J, Burden AC. An evaluation of the performance of the NHS Health Check programme in identifying people at high risk of developing type 2 diabetes. BMJ Open 2013;3:e002219.

35. Noble D, Mathur R, Dent T, et al. Risk models and scores for type 2 diabetes: systematic review. BMJ 2011;343:d7163.
36. Hippisley-Cox J, Coupland C. Predicting the risk of chronic kidney disease in men and women in England and Wales: prospective derivation and external validation of the QKidney Scores. BMC Fam Pract 2010;11:49.

37. Walter FM, Emery J, Braithwaite D, et al. Lay understanding of familial risk of common chronic diseases: a systematic review and synthesis of qualitative research. Ann Fam Med 2004;2:583-94.

38. Greenhalgh T, Helman C, Chowdhury AM. Health beliefs and folk models of diabetes in British Bangladeshis: a qualitative study. BMJ 1998;316:978-83.

39. Capewell S, Graham H. Will cardiovascular disease prevention widen health inequalities? PLoS Med 2010;7:e1000320.

40. Krogsboll LT, Jorgensen KJ, Gronhoj Larsen C, et al. General health checks in adults for reducing morbidity and mortality from disease: Cochrane systematic review and meta-analysis. BMJ 2012;345:e7191.

41. Daily Mail. Are NHS over-40 s health checks a waste of time? Critics say they're useless, 2013. http://www.dailymail.co.uk/health/article2397758/NHS-health-checks-40s-waste-time-Ministers-say-300mnational-programme-save-lives.html (accessed 6 May 2014).

42. Krogsboll LT, Jorgensen KJ, Gotzsche PC. Universal health checks should be abandoned. BMJ 2013;347:f5227.

43. Majeed A, Banarsee R. General health checks may not reduce morbidity or mortality but do increase the number of new diagnoses. Evid Based Nurs 2013;16:111-12.

44. Majeed A, Rawaf S, De Maeseneer J. Primary care in England: coping with financial austerity. Br J Gen Pract 2012;62:625-6. 